\title{
Workplace Hazard Faced by Vulnerable Migrant Workers Working in the Informal Sector at Lucknow City
}

\author{
Poonam Verma ${ }^{1 *}$ and Shalini Agarwal \\ 'Research Scholar, Department of Human Development and Family Studies, Babasaheb Bhimrao Ambedkar \\ University, (A Central University), Lucknow - 226025, Uttar Pradesh, India; vermanetid21@gmail.com \\ ${ }^{2}$ Associate Professor, Department of Human Development and Family Studies, Babasaheb Bhimrao Ambedkar \\ University, (A Central University), Lucknow - 226025, Uttar Pradesh, India
}

\begin{abstract}
Context: Workplace hazard is usually defined as working conditions that have potential to cause injury and/or illness to workers. Examples of hazards are exposed to hazardous substances; working with dangerous tools and equipment or performing potentially injurious task, such as repetitive movement and heavy lifting Aim: The purpose of this study was to investigate the prevalence of workplace hazard face of vulnerable migrant workers. Setting and Design: The study was carried out on eighty migrant workers comprising of male and female. The purposive sampling technique was adopted in the study. Data were collected using a 9 question survey tool developed by S. Peter et.al, Institute for work and health, Canada, in 2016. Materials and Methods: A self-structured and standardized interview schedule scale (OHS) devised by institute for work and health, Canada, in 2016 used for the purpose of the gathering information and measurement workplace hazard in different variables of the respondents. The study adopted survey research design and interviewed respondents personally. Statistical Analysis Used: The data were coded and analyzed using IBM SPSS20.0 Version. The level of workplace hazard in different segments was analyzed in the form of frequencies, mean, standard deviation and the significance was tested using ANOVA. Result: The study clearly showed that the maximum hazard in the workplace by migrant workers is to repeatedly repeat the same movement with hands or wrists, exposure to chemical, gas, and flammable substance, standing hours in the same posture and working for 2 meters. The hazard was felt in stand and working in greater heights. Conclusion: In the present study it has been found that the issue of occupational health among workers needs more attention. There was a risk of musculoskeletal problems and breathing problems and slipping while working in their stations. Measures are needed to improve the work environment of workplace safety staff that ensures the availability of personal protective equipment, good living condition and hygiene at the sites. In addition, the protection of workers' health is the responsibility to the community as well as local government and businessmen.
\end{abstract}

Keywords: Informal Sector, Vulnerable Migrant Workers, Workplace Hazard

\section{Background}

Migrant workers in the informal sector are usually daily wage laborers, whose day-to-day survival depends on their ability to work on that day. Because they are exposed to potentially hazardous working conditions and their health suffers due to overwork and exhaustion; they are often forced to take leave and on days that they take leave, they earn nothing. These workers are thus trapped in a vicious cycle and are faced with the dilemma of working and risking worsening their health and not working and losing out on money they need for food and shelter on a daily basis. Over $60 \%$ of workers in most groups said that they take more than 5 days of leave in a month. Added to this is the issue of non-payment of overtime wages in sectors like construction work. Nearly $50 \%$ of construction workers surveyed, who worked overtime were not paid overtime wages ${ }^{1}$.

In the last survey, conducted by NSSO in the year 2009-10, announced that there are 46.5 crores unorganized laborers in our country, out of those greater part, i.e. 43.7 crores are unorganized laborious and remaining 2.8 crores labor are from organized sectors. There are various categories of the labor force in unorganized sectors like agriculture and allied services. In those classifications, by far most of workers, i.e. 52\% are engaged in agriculture sectors and rest of labors are from non-agricultural services

*Author for correspondence 
like construction work, household work, bidi makers and mechanical/industrial work and many more. The most vital range that we are going to talk is concerned to migrant laborers' and their poor health conditions due to inaccessibility of basic amenities and their cleanliness, condition, not only that, but also about critical situations like poor living condition, poor compensation that they deal with their regular life ${ }^{2}$.

\section{Material and Methods}

\subsection{Selection of Subject}

Selection of subject- sample was selected from Lucknow city to carry out this research. Respondents were selected using purposive sampling technique. The entire Lucknow city is divided into five zones - east, west, north, south and central from these zones, randomly two zones were selected Aurangabad and Krishna Nagar from south and west zones, respectively were selected from the slums of migrant workers are majorly concentrated using purposive sampling from each area comprising of a total of eighty sampling. In which male migrant workerswere $51 \%$ and female migrant workers $48 \%$.

\subsection{Tools Used}

The questionnaire was applied to migrant workers for the assessment of workplace hazard faced problems. Occupational health and safety vulnerability scale by Peter Smith Institute for work and health, Canada, in $2016^{3}$ was used for the measurement of workplace hazard of the migrant workers.

\subsection{Data Collection}

The respondents were interviewed in person. Respondents from each location were subjected to an interview method for assessing along with observation that included several factors. That is associated with their work and its impact on their workplace hazard. The study adopted survey research design. The survey was conducted during NovemberDecember 2020. Age, work experience and working hour's independent variables and workplace hazard were taken as the dependent variable.

\subsection{Statistical Analysis}

The data were expressed as the mean and degree of freedom to evaluate statistical significance workplace characteristics. Score ranged from seven for never, once a year, every 6 months, every 3 months, every month, every week and every day. Gender, age marital status, work experience, working hours and monthly income were recorded categorical variable.
The data were coded and analysis using IBM SPSS20.0 version. The levels of workplace hazard were also calculated with the help of frequency percentage, mean, degree of freedom and significance was tested using ANOVA.

\section{Result}

The socio-demographic and occupational characteristics of thetotalsampleofmigrantworkersareexplainedin(Figure 1). The total percent of male and female were $52 \%$ and $48 \%$ respondents. This percentage is based on the number of these the number of males is slightly more than females. Their age ranged from $20-40$ years, out of $50 \%$ belonged to $35-40$ years and $21 \%$ belonged to $30-35$ years and only $6 \%$ belonged to $20-25$ years. In which $48 \%$ were non-vulnerable workers and $58 \%$ were vulnerable workers. It was found that there were $48 \%$ persons working a migrant more than 6 years, whereas only $8 \%$ are working for less than $0-2$ years. 58\% of the respondents were involved in work for 8-9 hours per day, whereas $20 \%$ only work for more than 9 hours. 25\% migrants workers reported that they have an income Rs. 4000-6000/- whereas, and 46\% earn Rs. 800010,000 per month.
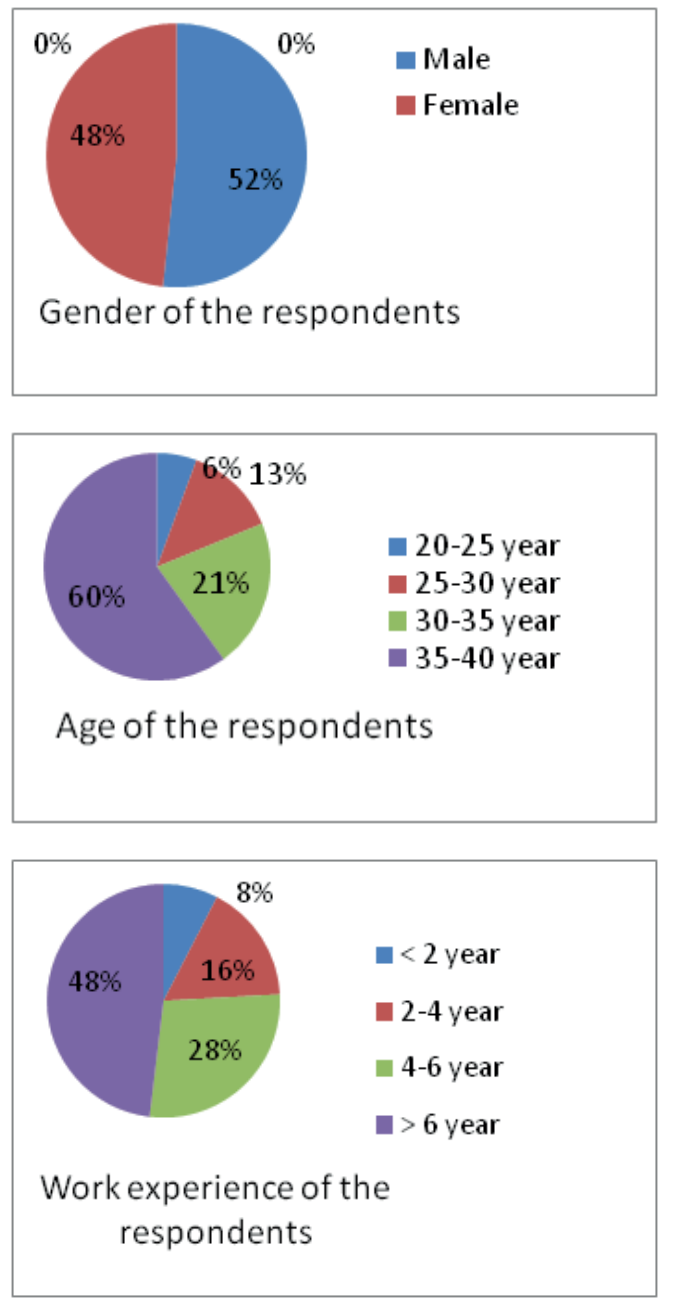

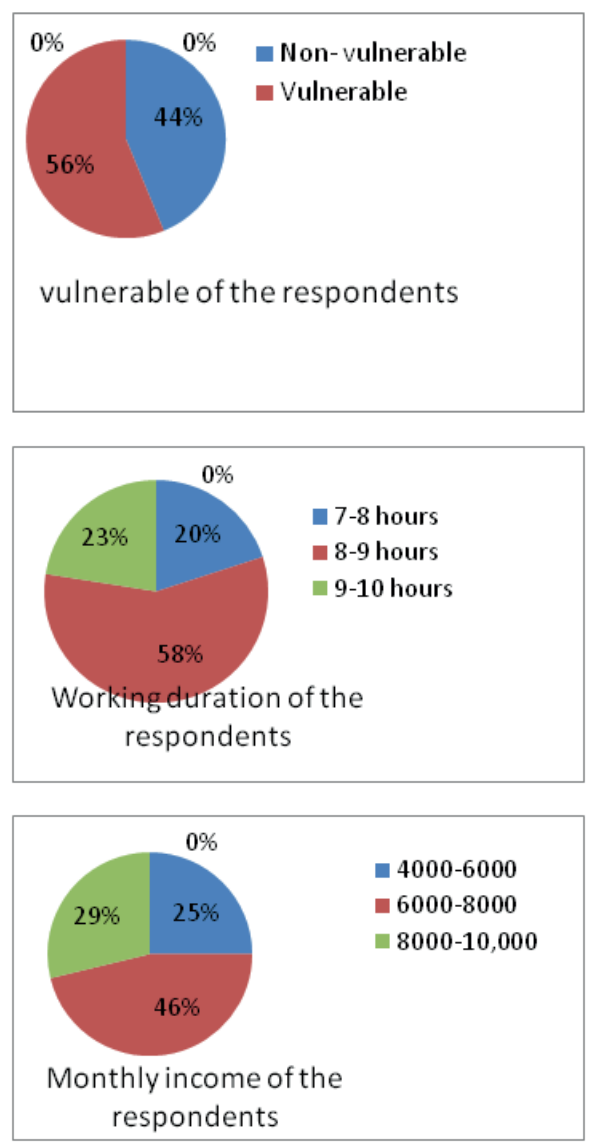

Figure 1. Sociodemographic and occupational characteristics of the migrant workers.

\section{Workplace Hazard Due to Age}

Responses of workplace related hazards according to age have been presented in (Table 2), maximum workers in the workplace hazard who were in the age group of 30 to 35 , weighted more heavily than $20 \mathrm{~kg}$ at least 10 times a day, while workers who faced the least hazard were in the age group of 25-30 year and doing the same task repeatedly with your hands or wrists for at least 3 hours a day, the maximum number of workers involved in such work was found to be in the age group 35-40 years and the minimum was found in the age group of 25-30 years. Apart from this, the work of which the workers were not familiar at all the workers of almost all ages. The maximum workers who came in contact with hazardous substances such as chemical flammable substance and gas were in the age group of 25-30 years and working hours in the same posture while working hours in the same posture while working in all age worker a similar hazard was found the maximum danger was found in the $30-40$ years age group among workers working standing 2 meters or more above the ground danger was found in the 20-30 age groups. Age of the workers working in the maximum noise level was 20-25 years and of the workers working in the minimum noise level was 35-40 years workers in the 35-40 age group were found to feel, more nervousness or discomfort was found in workers in the 20-25 age group the problems of feeling difficult or hazards in standing and working for more than 2 hours in a row was found in almost all age group workers.

Table 1. The results of the study hypotheses

\begin{tabular}{|c|c|c|c|c|c|c|}
\hline \multirow{3}{*}{ Item } & \multicolumn{4}{|c|}{ Age } & \multirow{3}{*}{$\mathrm{F}$} & \multirow{3}{*}{$\mathrm{P}$} \\
\hline & $20-25$ years & $25-30$ years & $30-35$ years & $35-40$ years & & \\
\hline & $M \pm S . D$ & $\mathrm{M} \pm \mathrm{S} . \mathrm{D}$ & $M \pm S . D$ & $M \pm S . D$ & & \\
\hline $\begin{array}{l}\text { Manually lift, carry or push items heavier } \\
\text { than } 20 \mathrm{~kg} \text {. atleast } 10 \text { time during the day. }\end{array}$ & $7.00 \pm .000$ & $4.71 \pm 2.986$ & $6.41 \pm 1.480$ & $6.38 \pm .957$ & 4.954 & .003 \\
\hline $\begin{array}{l}\text { Do repetitive movements with your hands } \\
\text { or wrists (Packing, sorting, assembling, } \\
\text { cleaning, pulling, pushing, typing) }\end{array}$ & $6.33 \pm 2.000$ & $6.71 \pm 1.309$ & $7.00 \pm .000$ & $7.00 \pm .000$ & 1.496 & .222 \\
\hline $\begin{array}{l}\text { Perform work task, or use work methods, } \\
\text { that you are not familiar with }\end{array}$ & $2.67 \pm 1.323$ & $2.00 \pm 1.378$ & $2.71 \pm 1.528$ & $2.00 \pm 1.461$ & 1.524 & .214 \\
\hline $\begin{array}{l}\text { Impact with hazardous substance such as } \\
\text { chemical's, flammable, liquids and gases }\end{array}$ & $7.00 \pm .000$ & $6.71 \pm 1.309$ & $7.00 \pm .000$ & $7.00 \pm .000$ & .934 & .428 \\
\hline Work in a bent, twisted or awkward work posture & $7.00 \pm .000$ & $7.00 \pm .000$ & $7.00 \pm .000$ & $7.00 \pm .000$ & $2 . .26$ & .117 \\
\hline $\begin{array}{l}\text { Work at a height that is } 2 \text { meters or more } \\
\text { above the ground or floor. }\end{array}$ & $4.33 \pm 1.225$ & $3.10 \pm 1.814$ & $3.59 \pm 1.987$ & $4.56 \pm 2.394$ & 1.217 & .310 \\
\hline $\begin{array}{c}\text { Work in noise levels that are so high that you } \\
\text { have raise your voice when talking to people } \\
\text { less than one meter away. }\end{array}$ & $5.44 \pm 2.603$ & $3.67 \pm 2.781$ & $4.59 \pm 2.536$ & $4.75 \pm 2.236$ & 3.588 & .017 \\
\hline Experience being bullied or harassed at work & $3.44 \pm 1.130$ & $4.57 \pm 1.287$ & $3.59 \pm 1.438$ & $7.00 \pm 1.025$ & 00 & 00 \\
\hline Stand for more than 2 hours in a raw. & $7.00 \pm .000$ & $7.00 \pm .000$ & $7.00 \pm .000$ & $7.00 \pm .000$ & 00 & 00 \\
\hline
\end{tabular}




\section{Workplace Hazard due to Working Experience}

The data depicted in (Table 1), clearly indicates that maximum workplace hazards workers who had more than 6 years of work experience, such worker lift or push heavy weights more than $20 \mathrm{~kg}$ atleast 10 times a day while working, while facing the least hazard doing workers whose experiences were less than 2 years. One had to do the same task repetitive with his hand or wrists for at least 3 hours a day. The work experience of the workers involved in such work was almost same 2-6 years. Significant difference was evident across the workers with varied work experience in repeating a single movement with hands or wrists, exposure to hazardous substances such as, chemicals, gas and flammable substances and working in the same posture are obvious. In addition, workers who were not familiar with the time were found to be at risk in doing such work. Maximum experience of doing these works was less than 2 years and at least 4-6 years of experience. Workers who had more than 6 years of experience in contact with hazardous substances such as chemicals, inflammable substance and gas while working at work, felt more threatened and the experience of workers standing in the same posture was almost the same 2-4 years. Those who worked standing on the ground or more found greater hazards. The workers involved in this work had a maximum experience of more 6 years and a minimum of 2-4 years of experience. Those working with the maximum noise levels who had work experience less than 2 years and workers who experienced nervousness or discomfort while working had experience of 4-6 years and minimum experience was more than 6 years.

Table 2. Variation in Workplace Hazard according to work Experience

\begin{tabular}{|c|c|c|c|c|c|c|}
\hline \multirow{3}{*}{ Item } & \multicolumn{4}{|c|}{ Working Experience } & \multirow{3}{*}{$\mathrm{F}$} & \multirow{3}{*}{$\mathrm{P}$} \\
\hline & $<2$ years & $2-4$ years & $4-6$ years & $>6$ years & & \\
\hline & $\mathrm{M} \pm \mathrm{S} . \mathrm{D}$ & $M \pm S . D$ & $\mathrm{M} \pm \mathrm{S} . \mathrm{D}$ & $\mathrm{M} \pm \mathrm{S} . \mathrm{D}$ & & \\
\hline $\begin{array}{l}\text { Manually lift, carry or push items heavier } \\
\text { than } 20 \mathrm{~kg} \text {. atleast } 10 \text { time during the day. }\end{array}$ & $7.00 \pm .000$ & $6.08 \pm 2.253$ & $4.95 \pm 2.554$ & $6.61 \pm 1.152$ & 5.238 & .0001 \\
\hline $\begin{array}{l}\text { Do repetitive movements with your hands } \\
\text { or wrists (Packing, sorting, assembling, } \\
\text { cleaning, pulling, pushing, typing) }\end{array}$ & $5.00 \pm 3.098$ & $7.00 \pm .000$ & $7.00 \pm .000$ & $7.00 \pm .000$ & 8.672 & .000 \\
\hline $\begin{array}{l}\text { Perform work task, or use work methods, } \\
\text { that you are not familiar with }\end{array}$ & $2.83 \pm 1.472$ & $2.54 \pm 1.127$ & $1.86 \pm 1.283$ & $2.58 \pm 1.638$ & 1.270 & .289 \\
\hline $\begin{array}{l}\text { Impact with hazardous substance such as } \\
\text { chemical's, flammable, liquids and gases }\end{array}$ & $7.00 \pm .000$ & $7.00+.000$ & $6.73+1.279$ & $7.00+.000$ & .647 & .631 \\
\hline $\begin{array}{l}\text { Work in a bent, twisted or awkward work } \\
\text { posture }\end{array}$ & $7.00 \pm .000$ & $7.00 \pm .000$ & $7.00 \pm .000$ & $7.00 \pm .000$ & 3.635 & .0009 \\
\hline $\begin{array}{l}\text { Work at a height that is } 2 \text { meters or more } \\
\text { above the ground or floor. }\end{array}$ & $4.33 \pm .816$ & $3.77 \pm 1.691$ & $7.00 \pm 1.405$ & $7.00 \pm 2.247$ & 7.080 & .000 \\
\hline $\begin{array}{l}\text { Work in noise levels that are so high that you } \\
\text { have raise your voice when talking to people } \\
\text { less than one meter away. }\end{array}$ & $6.17 \pm .543$ & $4.85 \pm .775$ & $2.36 \pm .549$ & $5.29 \pm .311$ & .500 & .736 \\
\hline Experience being bullied or harassed at work & $3.67 \pm .494$ & $3.69 \pm .429$ & $4.05 \pm .312$ & $3.66 \pm .208$ & 00 & 00 \\
\hline Stand for more than 2 hours in a raw. & $7.00 \pm .000$ & $7.00 \pm .000$ & $7.00 \pm .000$ & $7.00 \pm .000$ & 00 & 00 \\
\hline
\end{tabular}

\section{Discussion}

The study sample comprises of migrant worker from a different state (like Bihar, Assam, Jharkhand) because there is a lot of unemployment. This is the way they have to come here to work. They give them land to live on construction sites, industries and migrant workers doing domestic work and the contractor give them money on a daily or 15 day basis.
If we observe the socio-demographic profile of migrant workers, males (51\%) and female (48\%) were respondents. Studies in China ${ }^{4}$ and Himachal Pradesh ${ }^{5}$ show that $54 \%$ of male and $45 \%$ females; the finding are similar to our study. The study of population belonged to middle aged (20-40 years). Similar findings were found by a report submitted on migrant workers of $\mathrm{Nepal}^{6}$.

The majority of migrant workers were working as migrant worker more than $>6$ years and most $(58 \%)$ of them 
reported to work for 7-9 hours daily in the current study. R. Arul ${ }^{7}$. Found that $27 \%$ of migrant worker for period of 6-7 hours daily $26 \%$ more than 8 hours in Tiruchirappalli city. From the study, the average monthly income of $46.3 \%$ migrant worker is found to be $6000-8000$ INR.

The results of the present study showed that the maximum hazard was felt by respondents. When working in the working in the workplace whose work experience was more than 6 years. The prevalence of hazards work in the workplace among migrant workers, especially repeated of the same movement of the hands or wrists, exposure to hazardous substance such as chemicals, flammable substance gas, etc, $(\mu=7.00)$ to stand in at least the same posture and standing work for more than 2 hours continuously $(\mu=7.00)$. It ${ }^{8}$ found that high prevalence of risk of workplace hazards among migrant worker. The hazard of musculoskeletal pain was found when lifting or pushing more than $20 \mathrm{~kg}$. While working with 2 to 4 years and more than 6 years to work experience $(\mu=6.61)$. A method of working that workers were not familiar with was found to be a difference in the experience years of doing such work. In addition, the difference in the years of work experience was clearly observed among workers experiencing nervousness and discomfort at work.

Maximum workplace hazard repeating the same task more than 3 hours with hand or wrists, exposure to hazardous substance such as chemical, flammable substances hours in a single posture working standing, feeling nervous and distressed and working sting more than 2 hours in a raw was felt by the respondents. Whose age was 35-40. The hazard of lifting or pushing heavy weight was expressed equally among the respondents in the age group of 30-35 and 35-40. In tasks that were not familiar to you, the hazard of doing such work was expressed equally among the workers of almost all age groups $(\mu=2.71)$. The hazard of slipping while working standing at a high of meter or more above the ground was expressed by the respondents in the age group of 20-25 and 35-40 ( $\mu=4.33)$. Hearing problems with working in noise levels of machines were 30-35 expressed by workers who were 30-35 and 35-40 years of age and feel of nervousness and discomfort while working was expressed by working in the workplace, the difference of hazard was clearly found in the workers of different age groups.

MC. Randhika, 28 could 2015, Sahbhagi Shiksha Kendra (SSK)'s report on activity health problems faced by migrant staff in Ghaziabad consistently catalogues the daily health risks faced by 5 major activity, teams of migrants within the informal sector. Reviewing the notice of migrant staff regarding their rights and entitlements, and light key health issues, the report presents policy recommendations and stresses the pressing would like for reasonable and accessible care.
$\mathrm{An}^{10}$ operational examination on mishaps in devel oping industry revealed that issues emerging from laborers were $70 \%$, working environment issues $49 \%$, inadequacies with hardware $56 \%$ and insufficiencies with hazard the board $(84 \%) 11$. In our investigation, around $8 \%$ had supported business related mishap/injury during most recent 1 year. Helpless language aptitudes keep them from understanding the security insurances offered and to adhere to the directions given by managers. The predominance of wounds in past investigations was $7.9 \%, 7.56 \%, 6.6 \%$ and $25.42 \%$ individually.

$\mathrm{In}^{11}$ construction work mishaps add to $16.4 \%$ of lethal worldwide word related mishaps. Relative danger of mishaps in the Indian development industry was 8 contrasted with other assembling area and the deadly mishap recurrence rate was 15.8 occurrences/1000 workers/year.

\section{Conclusion}

The prevalence of workplace hazards and vulnerability is very high among migrant workers in the informal sector, the prevalence of working hours while standing in the same posture was reported to be high among experience and non-experience workers. In which they had many problems such as back pain, shoulder pain, injury due to lack of safety equipment, etc, these can high morbidities associated with them. Prevention is urgently needed to control the same. In addition, the protection of workers' health is the responsibility to the community as well as local government and businessmen.

\section{Acknowledgement}

Author's acknowledgesthe University Grant Commission Fellowship under the Ministry of Human Recourse Devel opment for supporting our study. We also wish to acknowledge the cooperation of the participants in sharing their valuable time to participate in this study.

\section{References}

1. Randhika MC. Invisible Dangers; Occupational health issues faced by migrant workers id Ghaziabad. 2015 May.

2. Subhasish C. Migrant labourers and their health and hygiene.International Journal of Emerging Trends in Science and Technology. 2016. http://dx.doi. org/10.18535/ijetst/v3i08.16

3. Smith P. Developing a framework for understanding and measuring occupational health \& safety vulnerability. 2016. http://www.iscrr.com.au/_data/assets/pdf_file/ 0011/297254/Developing-aFramework-for-Under standing-and-Measuring-OHS-vulnerability.pdf 
4. Li Zan, D. Junming et al. The mental health and depre ssion of rural-to-urban migrant workers compared to non-migrant workers in Shanghai: A cross-sectional study. International Journal of Health. 2019; S55-S63. PMid:31670817. https://doi.org/10.1093/inthealth/ihz0 81

5. Vivek T. A study on the socio economic profile of migrant labour in District Knagra (Himanchal Pradesh). International Journal Of Science and Research. ISSN (Online): 2319-7064 Index Copernicus Value. 2015: 78.9.

6. Rupakheti D, et al. Occupational safety and health vulnerability among brick factory workers in Dhading District,Nepal. Annals of Global Health. 2018; 84(3): 481-7. PMid:30835388 PMCid:PMC6748303. https:// doi.org/10.29024/aogh.2313

7. Arul R. A study on the socio-economic condition of women domestic workers in Tiruchirappalli City. International Journal of Latest Engineering and
Management Research. ISSN: 2455-4847. 2017 Dec; 02(12): 20-4. www.ijlemr.com

8. Rupakheti D, et.al. Occupational safety and health vulnerability among Brick factory workers in Dha ding Distric, Nepal. 2018. PMid:30835388 PMCid: PMC6748303. https.//doi,org/10.29024/aogh.2313 htt ps://www.annalsofglobalhealth.org/articles/10.29024/ aogh.2313/print/

9. Randhika MC. Invisible dangers; Occupational health issues faced by migrant workers id Ghaziabad. 2015 May.

10. Thayyil J, Bhasker R. Occupational health problem of construction workers in India. International Journal of Medicine and Public Health. 2013 Dec; 3. https://doi. org/10.4103/2230-8598.123415

11. Kulkarni GK.Construction industry: More needs to be done. Indian Journal of Occupational Environmental Medicine. 2007 Jan. 104103/0019- 527.32455 